\title{
ANALISIS TINGKAT KEPUASAN KONSUMEN TERHADAP KUALITAS LAYANAN SHOPEE
}

\author{
Ni Wayan Widya Ekarani ${ }^{1 \S}$, Ni Luh Putu Suciptawati ${ }^{2}$, Made Susilawati ${ }^{3}$ \\ ${ }^{1}$ Program Studi Matematika, Fakultas MIPA - Universitas Udayana [Email: widyaekarani25@gmail.com] \\ ${ }^{2}$ Program Studi Matematika, Fakultas MIPA - Universitas Udayana [Email: suciptawati@ unud.ac.id] \\ ${ }^{3}$ Program Studi Matematika, Fakultas MIPA - Universitas Udayana [Email: mdsusilawati@unud.ac.id] \\ ${ }^{\S}$ Corresponding Author
}

\begin{abstract}
The Covid-19 pandemic caused many people starting to switch to buying and selling online, some of them use Shopee e-commerce. The aim of this study is to analyze the factors that influence customer satisfaction with service quality and to analyze Shopee's service quality using confirmatory factor analysis and e-servqual analysis. The variables of this study are divided into seven dimensions of $e$ servqual, namely efficiency, fullfilment, system avaibility, privacy, responsiveness, compensation, and contact, with a total of 23 indicators. This study took a sample of 126 Shopee user respondents in Bali Province who had made transactions at least 3 times until 2021. The results of the factor analysis show that there really are seven dimensions that affect the quality of online services. The results of the e-servqual analysis obtained the value of consumer perceptions of service quality is 7.82 , this value was included in the satisfied category. The factors that require focus of attention are the dimensions of system availability, need to improve the system so that the server does not down easily during heavy traffic.
\end{abstract}

Keywords: e-servqual, factor analysis, Shopee, consumer satisfaction, electronic service quality.

\section{PENDAhUluAN}

Covid-19 berdampak besar terhadap semua bidang kehidupan, tidak terkecuali pada bidang bisnis. Santia (2020) melaporkan saat memasuki era new normal terjadi perubahan kebiasaan belanja konsumen disebabkan pandemi Covid-19. Kegiatan belanja online yang semula $4,7 \%$ mengalami peningkatan menjadi 28,9\% akibat pandemi Covid-19. Di Indonesia telah bermunculan berbagai macam marketplace terkenal seperti Shopee, Lazada, Tokopedia, Bukalapak, dan sebagainya. Husaini (2020) menyatakan bahwa Shopee adalah aplikasi belanja online yang paling diminati. Menurut situs berita tersebut, riset yang dilakukan terhadap 1000 responden dari seluruh Indonesia, 66\% konsumen memilih Shopee menjadi online shop yang paling diingat saat Ramadan dan Lebaran 2020, kemudian disusul Tokopedia sebesar 16\%, Lazada sebesar 12\%, Bukalapak 4\%, Blibli $1 \%$, JD.ID 1\%, disusul Akulaku, OLX, dan Sociolla. Oleh sebab itu, terdapat hal-hal yang perlu diperhatikan oleh pihak Shopee maupun penjual untuk mempertahankan kepercayaan pelanggannya, salah satunya yaitu kualitas layanan Shopee. Kualitas layanan memengaruhi kepuasan, niat untuk membeli pada konsumennya (Zeithaml et al., 2002). Konsumen akan merasa puas jika harapannya dipenuhi, bahkan akan merasa sangat puas apabila harapannya terlampaui. Pelanggan yang telah merasa puas, cenderung akan kembali membeli kemudian bercerita mengenai pengalamannya kepada temannya (Kotler \& Amstrong, 2008).

Dalam penelitian ini penulis meneliti faktorfaktor yang memengaruhi kepuasan konsumen terhadap kualitas layanan belanja online berdasarkan dimensi e-servqual di aplikasi maupun website Shopee serta menganalisis kualitas pelayanan Shopee. Penelitian serupa menggunakan metode analisis faktor dan servqual, salah satunya dilakukan oleh Yasa (2017) yang meneliti kepuasan nasabah pada kualitas layanan di LPD Sidakarya, mendapatkan hasil bahwa dari lima dimensi yang diteliti terdapat 4 dimensi yang menjadi fokus pembenahan kualitas yaitu mulai dari 
dimensi assurance, empathy, responsiveness, dan reliability.

Penelitian lain dilakukan oleh Sastika (2018). Menganalisis kualitas layanan Shopee di Kota Bandung menggunakan important performance analysis (IPA) memperoleh hasil tingkat harapan konsumen terhadap Shopee sangat tinggi sebesar $86,92 \%$, walapun tingkat kepuasan sudah cukup baik yaitu 68,78\% namun manajemen tetap harus lebih mengembangkan aplikasi demi memenuhi harapan konsumen dari beberapa faktor yang ditemui.

Analisis awal dalam penelitian ini menggunakan metode analisis e-servqual untuk mencari nilai servqual atau gap untuk dilanjutkan ke analisis faktor konfirmatori untuk pembentukan faktor kemudian kembali menganalisis e-servqual untuk mengetahui bagaimana kualitas pelayanan yang diberikan berdasarkan tujuh dimensi yaitu efficiency, fullfilment, system avaibility, privacy, responsiveness, compensation, dan contact.

\section{TINJAUAN PUSTAKA}

Menurut Kotler \& Keller (2016) kepuasan merupakan hubungan antara harapan dan penilaian seseorang atas kinerja yang dirasakan terhadap suatu produk. Jika kinerja dirasakan tidak sesuai harapan atau ekspektasinya, konsumen akan merasa kecewa. Jika sesuai dengan harapan atau ekspektasinya, konsumen akan merasa puas. Sedangkan jika melebihi dari harapannya, konsumen akan sangat senang. Kotler \& Keller juga menyatakan kepuasan akan dipengaruhi oleh kualitas produk dan layanan.

Kualitas layanan adalah hal yang wajib diperhatikan oleh perusahaan untuk mempertahankan pelanggannya, terlebih di persaingan yang semakin ketat ini. Pelayanan yang baik kepada konsumen akan memberikan kesan nyaman dan respek terhadap perusahaan. Berdasarkan definisi American Society for Quality, kualitas merupakan kemampuan dari fitur serta karakteristik produk atau layanan memenuhi kebutuhan yang diminta maupun tersirat oleh pelanggan.

Kualitas layanan elektronik tentu berbeda dengan kualitas layanan tradisional. Kualitas layanan elektronik merupakan kualitas yang dirasakan melalui pelayanan tidak langsung bertatap muka atau dari jarak jauh menggunakan jaringan internet sedangkan kualitas layanan tradisional merupakan kualitas yang dirasakan melalui pelayanan langsung tatap muka dengan konsumen. Parasuraman et al. (2005) mendefinisikan secara luas kualitas layanan elektronik untuk mencakup semua interaksi antara konsumen dengan situs, yaitu sejauh mana situs mampu memfasilitasi proses transaksi, pembelian, hingga pengiriman secara efektif dan efisien.

E-commerce dalam bahasa Indonesia berarti perdagangan secara elektronik atau online merupakan segala kegiatan jual-beli yang dilakukan menggunakan media elektronik. Laudon \& Laudon (2011) menyatakan ecommerce mengarah kepada pemanfaatan internet maupun web dalam bertransaksi bisnis.

E-Servqual merupakan pengembangan dari metode servqual. Servqual merupakan alat ukur kualitas pelayanan jasa yang dikembangkan oleh A. Parasuraman, Valerie A. Zeithaml, dan Leonard L. Berry dari tahun 1985, hingga akhirnya pada tahun 2005 mulai dikembangkan dimensi e-servqual yang akan digunakan khusus untuk mengukur kualitas layanan elektronik seperti e-commerce.

E-servqual memiliki empat dimensi dasar (Efficiency, System Availability, Fulfillment, Privacy) dan tiga dimensi tambahan (Responsiveness, Compensation, Contact) untuk menilai penanganan masalah layanan.

Analisis faktor adalah salah satu teknik analisis peubah banyak (multivariat) yang secara garis besar memiliki tujuan untuk menganalisis struktur keterkaitan (korelasi) di antara sejumlah besar variabel (misalnya, nilai tes atau item, tanggapan kuesioner, pola penggunaan media sosial, pelacakan digital) dengan mendefinisikan set variabel yang saling terkait, yang dikenal sebagai faktor atau komponen (Hair et al., 2019).

Model analisis faktor dalam notasi matriks menurut Johnson \& Wichern (2013) adalah:

$$
\boldsymbol{X}-\boldsymbol{\mu}_{(p \times 1)}=\boldsymbol{L}_{(p \times m)} \boldsymbol{F}_{(m \times 1)}+\boldsymbol{\varepsilon}_{(p \times 1)}
$$

Dengan $\mu_{i}$ menyatakan mean variabel $\mathrm{X}$ ke-i, $\varepsilon_{i}$ menyatakan spesifik faktor ke-i, $F_{j}$ menyatakan faktor ke-j, dan $\ell_{i j}$ menyatakan loading factor pada variabel ke-i dan faktor ke-j.

Penelitian ini akan menggunakan metode analisis faktor konfirmatori. Tahapan uji dalam analisis faktor adalah sebagai berikut: 
1) Uji asumsi analsisi faktor

Menurut Hair et al. (2019), asumsi dasar dalam analisis faktor yaitu terdapat beberapa struktur yang mendasari dalam kumpulan variabel yang dipilih yaitu keberadaan variabel berkorelasi. Metode untuk menentukan kesesuaian analisis faktor memeriksa keseluruhan matriks korelasi yaitu Bartlett test of sphericity untuk menguji adanya korelasi di antara variabel, dan Measure of Sampling Adequancy serta Kaiser Meyer Olkin (KMO) digunakan untuk menguji kecukupan sampel.

2) Ekstraksi faktor

Ekstraksi faktor merupakan suatu metode yang bertujuan untuk mereduksi data dari beberapa indikator kemudian menghasilkan jumlah faktor yang lebih ringkas atau sedikit. Menurut Johnson \& Wichern (2013) terdapat dua metode yang populer untuk estimasi parameter dalam ekstraksi faktor yaitu metode component analysis dan metode maximum likelihood. Namun dalam penelitian ini akan difokuskan pada metode component analysis. Nilai eigen dari satu faktor hanyalah jumlah kuadrat varian variabel pada faktor itu. Aturan sederhananya adalah jangan menyimpan faktor apa pun yang menyebabkan varian kurang dari satu variabel. Jadi, faktor yang dianggap signifikan hanya yang memiliki nilai eigen atau akar laten yang lebih besar dari 1 sedangkan semua faktor yang memiliki akar laten kurang dari $1(\lambda \leq 1)$ dianggap tidak signifikan dan diabaikan (Hair et al., 2019).

3) Penentuan jumlah faktor

Setelah melakukan ekstraksi faktor dapat dilakukan penentuan jumlah faktor sesuai dengan metode yang telah digunakan pada tahap ekstraksi. Adapun beberapa kriteria dalam menentukan jumlah faktor menurut Hair et al. (2019) yaitu kriteria a priori, kriteria akar laten, kriteria akar laten, dan kriteria uji scree.

\section{4) Rotasi Faktor}

Menurut Hair et al. (2019) alat terpenting dalam menafsirkan faktor adalah rotasi faktor. Efek pamungkas dari memutar matriks faktor adalah mendistribusikan kembali varians dari faktor sebelumnya ke faktor selanjutnya untuk mencapai yang lebih sederhana, secara teoretis lebih bermakna pola faktor. Terdapat dua metode rotasi faktor, yaitu rotasi orthogonal dan rotasi oblique.

5) Interpretasi hasil faktor

Pada analisis faktor konfirmatori akan dilihat faktor yang terbentuk sesuai teori atau konsep sebelumnya. Apabila terdapat penambahan faktor baru akan diberi penamaan pada faktor baru yang terbentuk sesuai dengan bobot dari masing-masing komponennya.

\section{METODE PENELITIAN}

Penelitian ini menggunakan data primer yang diperoleh dari penyebaran kuisioner dalam bentuk Google Form. Populasi pada penelitian ini adalah konsumen Shopee yang berdomisili di Provinsi Bali. Pengambilan sampel dilakukan dengan teknik purposive sampling yaitu sampel diambil dengan pertimbangan untuk situasi tertentu (Neuman, 2014), dengan kriteria sampel dalam penelitian ini yaitu konsumen Shopee yang berumur minimal 15 tahun atau sedang dalam sekolah menengah atas (SMA), berdomisili di Provinsi Bali, dan telah melakukan transaksi di Shopee minimal tiga kali sampai tahun 2021. Jumlah sampel dalam penelitian ini sebanyak 126 responden dan diperoleh 13 responden tiap kabupaten/kota di Provinsi Bali. Variabel pada penelitian ini dibagi menjadi dua berdasarkan persepsi dan harapan. Dimensi dan indikator dibentuk berdasarkan metode e-servqual yang dikembangkan oleh Parasuraman et al (2005), meliputi 23 indikator yang dikelompokkan menjadi tujuh dimensi e-servqual.

Untuk memperoleh faktor yang berpengaruh pada kepuasan konsumen terhadap kualitas layanan Shopee serta untuk mengetahui bagaimana selisih antara persepsi pelanggan dan ekspektasi konsumen terhadap pelayanan Shopee, penulis menggunakan metode analisis faktor kemudian analisis $e$ servqual dengan bantuan software SPSS. Berikut adalah langkah-langkah penelitian ini:

1) Menyebarkan kuesioner dalam bentuk google form yang disebarkan melalui sosial media.

2) Membentuk indikator baru $s$ yang mewakili kualitas yang dirasakan konsumen pada tiap item. Menurut Parasuraman et al., (1988) $s$ diperoleh dari selisih persepsi dan harapan konsumen.

$$
s_{j k}=P_{j k}-E_{j k}
$$

3) Uji kelayakaan kuisioner dengan uji validitas dan reliabilitas.

4) Menganalisis faktor dengan langkahlangkah sebagai berikut:

(1) melihat nilai Bartlett's test untuk menguji adanya korelasi antar variabel; 
(2) melihat nilai Kaiser Meyer Olkin (KMO) untuk mengetahui kecukupan sampel data yang telah diambil cukup untuk difaktorkan, dengan ketentuan nilai KMO harus lebih besar dari 0,5 ;

(3) melihat nilai Measure of Sampling Adequency (MSA) untuk setiap variabel sehingga diperoleh variabel manakah yang layak dilanjutkan ke dalam analisis faktor, dengan ketentuan apabila nilai MSA lebih dari 0,5 menunjukkan variabel tersebut bisa digunakan dan dianalisis lebih lanjut, jika tidak variabel tidak dapat dilanjutkan ke analisis atau harus dibuang;

(4) melakukan ekstraksi faktor untuk mereduksi data dan mendapatkan faktor menggunakan Principal Component Analysis;

(5) melakukan Rotasi Faktor Varimax untuk menyederhanakan struktur dengan mentransformasi faktor kemudian mendapatkan pola faktor sehingga mudah diinterpretasi;

(6) interpretasi terhadap faktor.

5) Menganalisis kembali dengan metode servqual:

(1) menganalisis tingkat kepuasan konsumen Shopee secara keseluruhan berdasarkan nilai servqual rata-rata total;

(2) memperoleh indikator yang memerlukan perhatian lebih dengan melihat nilai gap negatif terkecil pada nilai servqual;

(3) interpretasi hasil analisis.

\section{HASIL DAN PEMBAHASAN}

\subsection{Uji Validitas Dan Reliabilitas}

Diperoleh nilai korelasi Pearson untuk setiap indikator pada setiap dimensi memiliki nilai $r$ hitung (nilai korelasi pearson) lebih besar dari $r$ tabel untuk $\mathrm{n}=30$ yaitu 0,361 serta nilai signifikansinya kurang dari 0,05 sehingga seluruh indikator pada dimensi efisiensi dapat dikatakan valid atau cukup akurat untuk mewakili apa yang seharusnya. Untuk nilai Cronbach's Alpha pada setiap dimensi diperoleh lebih besar dari 0,6 maka semua dimensi dapat dikatakan reliabel atau dapat diartikan secara tepat (tidak ambigu).
Tabel 1. Luaran Uji Validitas

\begin{tabular}{|c|c|c|c|}
\hline Dimensi & Indikator & $\begin{array}{c}r \\
\text { pearson }\end{array}$ & $r$ tabel \\
\hline \multirow{5}{*}{ Efficiency } & E1 & 0,61 & 0,36 \\
\hline & E2 & 0,82 & 0,36 \\
\hline & E3 & 0,92 & 0,36 \\
\hline & E4 & 0,72 & 0,36 \\
\hline & E5 & 0,60 & 0,36 \\
\hline \multirow{4}{*}{ Fulliment } & $\mathrm{F} 1$ & 0,67 & 0,36 \\
\hline & $\mathrm{F} 2$ & 0,77 & 0,36 \\
\hline & F3 & 0,74 & 0,36 \\
\hline & $\mathrm{F} 4$ & 0,83 & 0,36 \\
\hline \multirow{2}{*}{ System Avaibility } & $\mathrm{S} 1$ & 0,93 & 0,36 \\
\hline & $\mathrm{S} 2$ & 0,92 & 0,36 \\
\hline \multirow{3}{*}{ Privacy } & $\mathrm{P} 1$ & 0,94 & 0,36 \\
\hline & $\mathrm{P} 2$ & 0,78 & 0,36 \\
\hline & P3 & 0,97 & 0,36 \\
\hline \multirow{4}{*}{ Responsiveness } & $\mathrm{R} 1$ & 0,92 & 0,36 \\
\hline & $\mathrm{R} 2$ & 0,95 & 0,36 \\
\hline & $\mathrm{R} 3$ & 0,89 & 0,36 \\
\hline & $\mathrm{R} 4$ & 0,89 & 0,36 \\
\hline \multirow{3}{*}{ Compensation } & K1 & 0,93 & 0,36 \\
\hline & $\mathrm{K} 2$ & 0,91 & 0,36 \\
\hline & K3 & 0,94 & 0,36 \\
\hline \multirow{2}{*}{ Contact } & $\mathrm{K} 1$ & 0,94 & 0,36 \\
\hline & $\mathrm{K} 2$ & 0,95 & 0,36 \\
\hline
\end{tabular}

Tabel 2. Luaran Uji Reliabilitas

\begin{tabular}{|l|c|}
\hline \multicolumn{1}{|c|}{ Dimensi } & Cronbach's Alpha \\
\hline Efficiency & 0,83 \\
\hline Fulliment & 0,86 \\
\hline System Avaibility & 0,84 \\
\hline Privacy & 0,93 \\
\hline Responsiveness & 0,93 \\
\hline Compensation & 0,90 \\
\hline Contact & 0,89 \\
\hline
\end{tabular}

\subsection{Uji Asumsi Analisis Faktor}

Setelah uji validitas dan reliabilitas, akan dilakukan uji asumsi analisis faktor. Diantaranya uji Bartlett, KMO, dan MSA.

Uji bartlet dirumuskan hipotesis:

$H_{0}$ : Matriks korelasi merupakan matriks identitas

$H_{1}$ : Matriks korelasi bukan matriks identitas 
Tabel 3. Luaran Uji Bartlett dan KMO

\begin{tabular}{|l|r|r|l|}
\hline \multirow{2}{*}{ Dimensi } & \multicolumn{2}{|c|}{$\begin{array}{r}\text { Bartlett's } \\
\text { Test of } \\
\text { Sphericity }\end{array}$} & \multirow{2}{*}{ Nilai } \\
\cline { 2 - 3 } & $\begin{array}{c}\text { Approx. } \\
\text { Chi- } \\
\text { Square }\end{array}$ & $\begin{array}{c}p \text { - } \\
\text { value }\end{array}$ & \\
\hline Efficiency & 160,10 & 0,00 & 0,76 \\
\hline Fulfillment & 185,62 & 0,00 & 0,70 \\
\hline System Avaibility & 39,30 & 0,00 & 0,50 \\
\hline Privacy & 187,58 & 0,00 & 0,72 \\
\hline Responsiveness & 221,64 & 0,00 & 0,73 \\
\hline Compensation & 172,62 & 0,00 & 0,73 \\
\hline Contact & 38,90 & 0,00 & 0,50 \\
\hline
\end{tabular}

Diperoleh luaran pada tabel nilai Uji Bartlett setiap dimensi menghasilkan p-value 0,000 kurang dari 0,5 sehingga tolak $\mathrm{H}_{0}$ jadi matriks korelasi yang dibentuk bukan matriks identitas artinya variabel memiliki korelasi yang cukup untuk dilanjutkan ke analisis faktor.

Untuk nilai KMO setiap dimensi lebih besar atau sama dengan 0,5 jadi data telah memenuhi syarat kecukupan sampel dan layak dilanjutkan ke analisis faktor

Tabel 4. Luaran Uji MSA

\begin{tabular}{|c|c|c|}
\hline Dimensi & Indikator & MSA \\
\hline \multirow{5}{*}{ Efisiensi } & E1 & 0,74 \\
\hline & E2 & 0,74 \\
\hline & E3 & 0,77 \\
\hline & E4 & 0,77 \\
\hline & E5 & 0,80 \\
\hline \multirow{4}{*}{ Pemenuhan } & $\mathrm{F} 1$ & 0,67 \\
\hline & $\mathrm{F} 2$ & 0,67 \\
\hline & F3 & 0,76 \\
\hline & $\mathrm{F} 4$ & 0,73 \\
\hline \multirow{2}{*}{$\begin{array}{l}\text { Ketersediaan } \\
\text { Sistem }\end{array}$} & S1 & 0,50 \\
\hline & S2 & 0,50 \\
\hline \multirow{3}{*}{ Privasi } & P1 & 0,69 \\
\hline & $\mathrm{P} 2$ & 0,72 \\
\hline & $\mathrm{P} 3$ & 0,78 \\
\hline \multirow{4}{*}{ Responsivitas } & $\mathrm{R} 1$ & 0,68 \\
\hline & $\mathrm{R} 2$ & 0,68 \\
\hline & R3 & 0,80 \\
\hline & R4 & 0,80 \\
\hline \multirow{3}{*}{ Kompensasi } & K1 & 0,71 \\
\hline & $\mathrm{K} 2$ & 0,74 \\
\hline & K3 & 0,74 \\
\hline \multirow{2}{*}{ Kontak } & $\mathrm{C} 1$ & 0,50 \\
\hline & $\mathrm{C} 2$ & 0,50 \\
\hline
\end{tabular}

Diperoleh nilai MSA pada setiap indikator lebih besar atau sama dengan 0,5 sehingga setiap indikator memiliki keterkaitan antar indikator yang cukup kuat sehingga dapat dilanjutkan ke analis faktor.

\subsection{Komunalitas}

Komunalitas digunakan untuk melihat varian dari indikator, nilai komunalitas yang kurang dari 0,5 tidak dapat lanjut digunakan ke dalam analisis karena tidak memiliki varians yang cukup menjelaskan variabel tersebut (Hair et al., 2019)

Diperoleh bahwa semua indikator komunalitasnya lebih dari 0,5 kecuali indikator E1 dan E5. Sehingga E1 dan E5 dikeluarkan dari analisis karena tidak memiliki varians yang cukup untuk dilanjutkan ke analisis faktor. Setelah indikator E1 dan E5 dikeluarkan dari analisis, diperoleh nilai komunalitas yang baru telah memenuhi syarat yaitu lebih dari 0,5 .

Tabel 5. Komunalitas untuk Setiap Dimensi

\begin{tabular}{|c|c|c|}
\hline Dimensi & Indikator & $\begin{array}{c}\text { Nilai } \\
\text { Communality }\end{array}$ \\
\hline \multirow{5}{*}{ Efficiency } & E1 & 0,39 \\
\hline & E2 & 0,58 \\
\hline & E3 & 0,63 \\
\hline & E4 & 0,60 \\
\hline & E5 & 0,40 \\
\hline \multirow{4}{*}{ Fulfillment } & $\mathrm{F} 1$ & 0,72 \\
\hline & $\mathrm{F} 2$ & 0,63 \\
\hline & F3 & 0,56 \\
\hline & $\mathrm{F} 4$ & 0,61 \\
\hline \multirow{2}{*}{ System Avaibility } & S1 & 0,76 \\
\hline & $\mathrm{S} 2$ & 0,76 \\
\hline \multirow{3}{*}{ Privacy } & $\mathrm{P} 1$ & 0,83 \\
\hline & $\mathrm{P} 2$ & 0,80 \\
\hline & P3 & 0,75 \\
\hline \multirow{4}{*}{ Responsiveness } & $\mathrm{R} 1$ & 0,75 \\
\hline & $\mathrm{R} 2$ & 0,75 \\
\hline & $\mathrm{R} 3$ & 0,60 \\
\hline & $\mathrm{R} 4$ & 0,58 \\
\hline \multirow{3}{*}{ Compensation } & K1 & 0,80 \\
\hline & $\mathrm{K} 2$ & 0,77 \\
\hline & $\mathrm{K} 3$ & 0,77 \\
\hline \multirow{2}{*}{ Contact } & $\mathrm{C} 1$ & 0,76 \\
\hline & $\mathrm{C} 2$ & 0,76 \\
\hline
\end{tabular}




\subsection{Ekstraksi Faktor}

Ekstraksi faktor menggunakan metode component analysis dengan mencari nilai eigen dari setiap indikator di dalam dimensi, kemudian indikator dengan nilai eigen lebih besar dari 1 dianggap signifikan sebagai faktor.

Tabel 6. Nilai Eigen Pada Setiap Dimensi

\begin{tabular}{|c|c|c|}
\hline Dimensi & Component & Total \\
\hline \multirow{3}{*}{ Efficiency } & 1 & 1,99 \\
\hline & 2 & 0,57 \\
\hline & 3 & 0,43 \\
\hline \multirow{4}{*}{ Fulliment } & 1 & 2,55 \\
\hline & 2 & 0,74 \\
\hline & 3 & 0,43 \\
\hline & 4 & 0,26 \\
\hline \multirow{2}{*}{ System Avaibility } & 1 & 1,52 \\
\hline & 2 & 0,47 \\
\hline \multirow{3}{*}{ Privacy } & 1 & 2,38 \\
\hline & 2 & 0,36 \\
\hline & 3 & 0,25 \\
\hline \multirow{4}{*}{ Responsiveness } & 1 & 2,70 \\
\hline & 2 & 0,60 \\
\hline & 3 & 0,48 \\
\hline & 4 & 0,20 \\
\hline \multirow{3}{*}{ Compensation } & 1 & 2,35 \\
\hline & 2 & 0,34 \\
\hline & 3 & 0,30 \\
\hline \multirow{2}{*}{ Contact } & 1 & 1,52 \\
\hline & 2 & 0,48 \\
\hline
\end{tabular}

Berdasarkan hasil nilai eigen yang diperoleh, didapat satu faktor atau satu komponen yang memiliki nilai eigen lebih besar dari 1 pada setiap dimensi, yaitu komponen dengan nilai eigen 1,$995 ; 2,553$; 1,$522 ; 2,384 ; 2,701 ; 2,351 ; 1,52$; sehingga memang benar faktor yang terbentuk adalah tujuh faktor hal ini sesuai dengan tujuh dimensi e-servqual.

\subsection{Rotasi Faktor}

Karena analisis ini menggunakan analisis faktor konfirmatori dan telah diperoleh satu faktor dari setiap dimensi maka rotasi faktor tidak lagi digunakan.

\subsection{Loading Factor}

Jumlah sampel memutuskan loading factor mana yang signifikan, karena jumlah sampel yang digunakan dalam penelitian ini adalah 126, nilai minimal loading factor yang signifikan adalah 0,5. Nilai loading yang diperoleh dari setiap indikator dalam dimensi adalah lebih dari 0,5 jadi dapat disimpulkan bahwa semua indikator memiliki nilai loading yang signifikan.

Berdasarkan analisis faktor diperoleh bahwa memang benar terdapat tujuh faktor untuk mengukur kualitas layanan elektronik sesuai dengan dimensi e-servqual yaitu efficiency, fullfilment, system avaibility, privacy, responsiveness, compensation, dan contact. Selanjutnya akan dilakukan analisis $e$ servqual untuk melihat tingkat kepuasan konsumen terhadap kualitas layanan Shopee dan faktor apa yang menjadi fokus pembenahan untuk pihak Shopee.

Tabel 7. Luaran Nilai Loading Factor

\begin{tabular}{|l|c|c|}
\hline \multirow{4}{*}{ Dimensi } & Indikator & $\begin{array}{c}\text { Nilai } \\
\text { Loading }\end{array}$ \\
\hline \multirow{4}{*}{ Efficiency } & $\mathrm{E} 2$ & 0,78 \\
\cline { 2 - 3 } Fulfillment & $\mathrm{E} 3$ & 0,84 \\
\cline { 2 - 3 } & $\mathrm{E} 4$ & 0,81 \\
\hline & $\mathrm{F} 1$ & 0,85 \\
\cline { 2 - 3 } & $\mathrm{F} 2$ & 0,79 \\
\cline { 2 - 3 } & $\mathrm{F} 3$ & 0,75 \\
\cline { 2 - 3 } System Avaibility & $\mathrm{F} 4$ & 0,78 \\
\hline \multirow{4}{*}{ Privacy } & $\mathrm{S} 1$ & 0,87 \\
\cline { 2 - 3 } & $\mathrm{S} 2$ & 0,87 \\
\hline \multirow{4}{*}{ Responsiveness } & $\mathrm{P} 1$ & 0,91 \\
\cline { 2 - 3 } & $\mathrm{P} 2$ & 0,89 \\
\cline { 2 - 3 } & $\mathrm{P} 3$ & 0,86 \\
\cline { 2 - 3 } & $\mathrm{R} 1$ & 0,86 \\
\cline { 2 - 3 } & $\mathrm{R} 2$ & 0,87 \\
\cline { 2 - 3 } & $\mathrm{R} 3$ & 0,77 \\
\hline \multirow{5}{*}{ Compensation } & $\mathrm{R} 4$ & 0,76 \\
\cline { 2 - 3 } & $\mathrm{K} 1$ & 0,89 \\
\hline \multirow{4}{*}{ Contact } & $\mathrm{K} 2$ & 0,88 \\
\hline \multirow{5}{*}{} & $\mathrm{K} 3$ & 0,88 \\
\hline & $\mathrm{C} 1$ & 0,87 \\
\hline & $\mathrm{C} 2$ & 0,87 \\
\hline
\end{tabular}




\subsection{Analisis E-Servqual}

Secara keseluruhan diperoleh ekspektasi konsumen terhadap kualitas layanan Shopee cukup tinggi yaitu dengan rata-rata sebesar 8,60282954 karena Shopee merupakan marketplace paling populer di Indonesia saat ini. Namun persepsi konsumen ternyata masih kurang dari rata-rata ekspektasinya yaitu sebesar 7,82298137 sehingga memiliki gap rata-rata sebesar $-0,7798482$.

Nilai gap sebesar $-0,7798482$ berarti ekspektasi konsumen lebih besar sebanyak 0,77 satuan dari persepsinya yang dirasakan terhadap kualitas layanan Shopee. Sehingga diperlukan evaluasi dari penyedia layanan untuk memperbaiki kembali kualitas layanan sehingga persepsi konsumen tidak lagi lebih rendah dari ekspektasinya, bahkan jika persepsi dapat melampaui ekspektasi konsumen akan merasa sangat puas dan dapat meningkatkan loyalitasnya terhadap perusahaan

Walaupun demikian nilai persepsi 7,82608696 dari skala 10 sudah termasuk kategori puas menurut Widodo \& Sutopo (2018).

Tabel 8. Urutan Prioritas Pembenahan

\begin{tabular}{|l|c|l|}
\hline \multicolumn{1}{|c|}{ Dimensi } & $\begin{array}{c}\text { Nilai E- } \\
\text { Servqual }\end{array}$ & Prioritas \\
\hline $\begin{array}{l}\text { System } \\
\text { Avaibility }\end{array}$ & $-1,38$ & I \\
\hline Compensation & $-0,93$ & II \\
\hline Responsiveness & $-0,87$ & III \\
\hline Privacy & $-0,80$ & IV \\
\hline Fulfillment & $-0,80$ & V \\
\hline Contact & $-0,76$ & VI \\
\hline Efficiency & $-0,33$ & VII \\
\hline
\end{tabular}

Tabel 8 menunjukkan urutan nilai servqual yang diperoleh mulai dari gap negatif terbesar hingga terkecil. Terlihat gap tertinggi dimiliki oleh dimensi system avaibility atau ketersediaan sistem yaitu sebesar -1,38. Oleh karena itu, diperlukan fokus lebih pada setiap indikator pada dimensi ini dengan pembenahan dan pembaruan lagi pada sistem agar server tidak mudah down dan eror saat traffic padat khususnya saat ada pesta diskon. Sedangkan untuk dimensi lainnya juga terus memerlukan pembenahan sampai dapat memenuhi ekspektasi konsumen yang cukup tinggi.

\section{SIMPULAN DAN SARAN}

\subsection{Simpulan}

Hasil penelitian menggunakan analisis faktor dengan menggunakan data kuesioner kepuasan konsumen terhadap kualitas layanan Shopee diperoleh bahwa memang benar terdapat tujuh dimensi yang memengaruhi kepuasan konsumen terhadap kualitas layanan elektronik yaitu efficiency, system availability, fulfillment, privacy, responsiveness, compensation, dan contact.

Berdasarkan hasil analisis e-servqual diperoleh persepsi konsumen terhadap kualitas layanan Shopee termasuk dalam kategori puas dengan nilai persepsi 7,82, namun demikian kualitas layanan Shopee memiliki gap negatif sebesar -0,77 karena konsumen Shopee memiliki ekspektasi yang cukup tinggi terhadap perusahaan ini yaitu sebesar 8,60 hal ini dikarenakan Shopee merupakan marketplace paling populer di Indonesia saat ini.

Adapun faktor yang menjadi fokus perhatian dengan gap negatif tertinggi yaitu 1,38 adalah dimensi ketersediaan sistem. Perlu dibenahi lagi pada sistem agar server tidak mudah down saat traffic padat khususnya saat ada pesta diskon. Sedangkan untuk dimensi lainnya juga terus memerlukan pembenahan sampai dapat memenuhi ekspektasi konsumen yang tinggi karena masih memiliki gap negatif dimulai dari dimensi kompensasi, responsivitas, privasi, pemenuhan, kontak, dan efisiensi.

\subsection{Saran}

Untuk pihak Shopee diharapkan untuk terus melakukan pembenahan di bidang kualitas layanan karena meskipun persepsi konsumen sudah dalam kategori puas, kualitas layanan Shopee memperoleh gap negatif yang menunjukkan ekspektasi konsumen masih lebih besar dari persepsinya. Sehingga perlu evaluasi pembenahan lebih serius pada pelayanan konsumen dengan memerhatikan faktor-faktor yang berpengaruh agar dapat meningkatkan persepsi konsumen sesuai dengan ekspektasi yang dibentuknya. Demi mempertahankan kepercayaan konsumen yang telah memberi harapan tinggi terhadap perusahaan, terlebih pada persaingan ketat e-commerce dewasa ini. Khususnya faktor ketersediaan sistem yang perlu menjadi fokus pembenahan, diperlukan terus-menerus upgrade sistem baik itu situs 
maupun aplikasi agar tetap stabil di keadaan apa pun.

Sedangkan untuk peneliti selanjutnya, bisa dikembangkan penelitian kualitas layanan menggunakan e-commerce lainnya sebagai perbandingan analisis kualitas layanan berbasis elektronik.

\section{DAFTAR PUSTAKA}

Hair, J. F., Black, W. C., Babin, B. J., Anderson, R. E., Black, W. C., \& Anderson, R. E. (2019). Multivariate Data Analysis. https://doi.org/10.1002/9781119409137.ch4

Husaini, A. (2020). Riset Snapcart: Shopee Paling Diminati dan Jadi Pilihan Konsumen Belanja. Kontan.Co.Id, 53679909. https://industri.kontan.co.id/news/risetsnapcart-Shopee-paling-diminati-dan-jadipilihan-konsumen-berlanja

Johnson, R. A., \& Wichern, D. W. (2013). Applied Multivariate Statistics (sixth). Pearson Education.

Kotler, P., \& Amstrong, G. (2008). PrinsipPrinsip Pemasaran edisi 12 (12th ed.). Penerbit Erlangga.

Kotler, P., \& Keller, K. L. (2016). Marketing Management (Global). Pearson Education.

Laudon, K. C., \& Laudon, J. P. (2011). Management Information Systems: Managing the Digital Firm. In Revista de Administração Contemporânea (Vol. 7, Issue 1). https://doi.org/10.1590/s141565552003000100014

Neuman, W. L. (2014). Social Research Methods: Qualitative and Quantitative Approaches. In Teaching Sociology (Vol. 30, Issue 3).

https://doi.org/10.2307/3211488

Parasuraman, A., Berry, L. L., \& Zeithaml, V. A. (1988). SERVQUAL: A Multiple-Item Scale for Measuring Consumer Perceptions Of Service Quality. Journal of Retailing, 64(1), 12-40.

Parasuraman, A., Zeithaml, V. A., \& Malhotra, A. (2005). E-S-QUAL A Multiple-Item Scale for Assessing Electronic Service Quality. Journal of Service Research, 7(3), 213-233.

https://doi.org/10.1177/1094670504271156
Santia, T. (2020). Aktivitas Belanja Online Naik 28,9 Persen Saat Pandemi covid-19. Liputan6.Com, 1. https://www.liputan6. $\mathrm{com} / \mathrm{bisnis} / \mathrm{read} / 4274623 /$ aktivitas-belanja -online-naik-289-persen-saat-pandemicorona

Sastika, W. (2018). Analisis Kualitas Layanan dengan Menggunakan E-service Quality untuk Mengetahui Kepuasan Pelanggan Belanja Online Shoppe (Studi Kasus: Pelanggan. Journals.Upi-Yai.Ac.Id, 2, 6. http:// journals.upi-yai.ac.id/index.php/ikr aith-humaniora/article/download/127/56

Widodo, S. M., \& Sutopo, J. (2018). Metode Customer Satisfaction Index (CSI) untuk Mengetahui Pola Kepuasan Pelanggan Pada E-commerce Model Business to Customer. Jurnal Informatika Upgris, 4(1), 38-45.

Yasa, P. A., Suciptawati, N. L. P., \& Susilawati, M. (2017). Implementasi Analisis Faktor Dalam Menganalisis Kepuasan Nasabah Terhadap Kualitas Layanan (Studi Kasus: Lpd Sidakarya). EJournal Matematika, 6(2), 152-160.

Zeithaml, V. A., Parasuraman, A., \& Malhotra, A. (2002). Service Quality Delivery Through Web Sites: A Critical Review Of Extant Knowledge. Journal of the Academy of Marketing Science, 30(4), 362-375. https://doi.org/10.1177/009207002236911 